\title{
Gêneros textuais e letramento
}

\section{Genre and literacy}

Maria do Socorro Oliveira*

Universidade Federal do Rio Grande do Norte

\begin{abstract}
RESUMO: Neste painel, discutimos a relação 'letramento' e 'gênero textual', considerando a rica complexidade que envolve não apenas esses objetos teóricos mas também a sua aplicação no domínio pedagógico, particularmente no que diz respeito ao ensino-aprendizagem de língua materna. Vincularemos a discussão a nossa experiência de ensino, pesquisa e extensão desenvolvida em programas de formação de professores, voltados para a mobilização de práticas transdisciplinares de natureza colaborativa e fortalecedora da ação docente. Nessa direção, indicamos os projetos de letramento como uma alternativa para o desenvolvimento de um trabalho contextualizado com os gêneros textuais.
\end{abstract}

PALAVRAS-CHAVE: Letramento; gênero; formação de professor; ensinoaprendizagem de língua materna; projetos de letramento.

ABSTRACT: Our contribution to this panel intends to discuss how 'literacy' and 'genres' are related, taking into account the complexity involving not only these two theoretical concepts, but also their implementation in the pedagogical domain, especially related to mother tongue learning-teaching. We intend to discuss that based on our experience in teaching, research and extension developed at teacher education programs aiming at transdisciplinary practices of colaborative and strengthening nature. To accomplish this task, we suggest literacy projects as an alternative to develop a contextualized work with genres.

KEYWORDS: Literacy; genre; teacher education; mother tongue learningteaching; literacy projects.

\section{Introdução}

Resultado das discussões empreendidas nas universidades nas décadas de 70 e 80 e dos programas de renovação de ensino introduzidos nas diretrizes curriculares dos estados e municípios e nos materiais destinados à formação continuada de professores, os Parâmetros Curriculares Nacionais (PCN) coleção de documentos publicados pelo Ministério de Educação e Cultura em 1997 - inauguram uma importante e desafiadora fase na educação brasileira

*msoliveira@digi.com.br 
que gera resistências por parte daqueles mais apegados a concepções tradicionais de ensino e se apresenta como uma dificuldade para os professores que, por falta de formação adequada, sentem-se inseguros e / ou incapazes de implementar práticas didáticas inovadoras fundamentadas em um conjunto de teorias até então desconhecidas como objetos de ensino.

Com vistas à preparação de professores e de outros agentes educativos para as mudanças propostas nos PCN, é bem verdade que o próprio MEC procurou assegurar o estudo e o debate dessas orientações curriculares mediante a realização de programas e projetos que atendessem, de forma ampla, à comunidade educacional brasileira. Também nessa perspectiva, outros órgãos oficiais (Secretarias de Educação do Estado e do Município, Diretorias de Ensino etc.) promoveram, e continuam promovendo, cursos, encontros e debates para que os professores se apropriem dessa nova orientação e dos objetos teóricos que a integram. No Brasil inteiro, instituiçōes formadoras voltaram-se para a educação do professor. Dentre os diversos programas instituídos para tal fim, serve como exemplo o Programa de Qualificação Profissional para a Educação Básica (PROBÁSICA) cujo objetivo primeiro era desenvolver uma política de formação para professores já no exercício da docência, mas sem titulação acadêmica, a qual lhes possibilitasse a construção de saberes teóricos e aplicados necessários a uma prática reflexiva e crítica em sala de aula.

Graças a esse esforço, não há dúvida de que uma gama de conceitos, oriundos de várias áreas, especialmente da linguística teórica e aplicada, instalouse no discurso do professor. Não apenas nos grandes centros educacionais mas também naqueles situados nos mais afastados rincões desse Brasil, a fala dos educadores brasileiros nunca esteve tão recheada de 'modismos' teóricos quanto agora. $\mathrm{Na}$ voz dos professores, o que se ensina agora são os gêneros textuais, sugeridos e explorados pelos livros didáticos, segundo uma perspectiva de letramento. Os professores também dizem que é preciso alfabetizar letrando e não há dúvida de que a linguagem é uma prática social. Esse discurso, embora revelador de que o professor fez ecoar a voz dos PCN, não se tem efetivado na prática do professor. Sobre isso, temos nos perguntado se, de fato, esses professores se apropriaram de tais conceitos ou se não houve apenas uma 'popularização' de determinados referenciais teóricos. A nossa experiência em contextos de formação indica que a apropriação dessas noções não se tem efetivado do modo esperado ou desejável. Quando averiguamos a atribuição de sentido que é construída por grande parte dos professores, depreendemos que se trata de um discurso 'vazio', com significaçôes distorcidas e banalizadas. 
Desse modo, se, por um lado, podemos confirmar que os professores passaram a falar, por exemplo, de noções como 'letramento' e 'gênero textual, graças à divulgação desses termos pelos $\mathrm{PCN}$ e ao impacto de processos formativos oferecidos aos professores, por outro lado, a mobilização desses saberes no contexto de sala de aula mostra-se problemática. Na busca de uma apropriação que não se efetivou, o professor acaba desenvolvendo um trabalho intuitivo que mistura práticas tradicionais com um discurso pretensamente inovador, caracterizado por entendimentos equivocados. E não poderia ser de outra maneira! Como poderiam ter um entendimento claro e se sentirem seguros acerca desses novos princípios se a própria Academia os reconhece como tão complexos, sendo ainda foco de acirrados debates por parte de seus membros? Transformar 'saberes científicos' em 'saberes a serem ensinados' na práxis escolar não é um trabalho fácil!

Tendo em vista essa problemática, as perguntas que orientam a nossa reflexão neste painel são: 1) Que contribuiçõos podem trazer os estudos de letramento e gênero para o letramento do professor?; 2) Como desenvolver com os professores práticas de letramento acadêmicas (formação inicial e continuada) que sejam significativas para o trabalho cognitivo, social e político no letramento escolar?; 3) Uma visão canônica do letramento aliada a uma abordagem de gêneros centrada no ensino explícito dos textos valorizados nas culturas dominantes assegura o desenvolvimento da competência leitora e escritora de aprendizes oriundos de variados contextos sociais?; O letramento cultural impacta de igual forma ou garante, de modo integral, a inclusão?

Em suma: em face do reconhecimento da diversidade social, dos inúmeros contextos em que as práticas de leitura e escrita ocorrem, dos diferentes modos que as constituem e dos diversos valores que a ela são atribuídos, como tratar o letramento e os gêneros textuais, de modo a provocar impactos na formação docente e na apropriação de práticas letradas significativas pelo aprendiz de língua, favorecendo, naturalmente, a inclusão social?

Responder a essas perguntas, considerando o modo como os professores têm significado as orientações dos PCN e atuado na sala de aula, implica discutir a rica complexidade que envolve não apenas os objetos teóricos - letramento e gênero - mas também a aplicação desses conceitos no domínio pedagógico, particularmente no que diz respeito ao ensino-aprendizagem de língua materna.

Faremos isso a partir da nossa história de ensino, pesquisa e extensão desenvolvida junto a professores que trabalham em favor de grupos desfavorecidos social e economicamente - crianças moradoras de favelas ou pertencentes à zona rural e jovens e adultos que lutam para ter acesso a bens 
culturais e oportunidades sociais que se oferecem num mundo em constante transformação, palco da pós-modernidade e das novas Tecnologias da Informação e Comunicação (TIC).

\section{Situando a questão}

Como qualquer iniciativa de natureza oficial (apesar de se preocupar com os interesses e necessidades da comunidade escolar a quem é destinada, ao levar em conta a cultura local dos seus membros - os alunos e os professores -, como interlocutores), a aplicação dos PCN (aqui falo de língua portuguesa) apresenta um caráter generalizante, prescritivo e hegemônico, na medida que se constitui numa iniciativa de caráter amplo, nacional que visa oferecer princípios teóricos e diretrizes gerais para o ensino-aprendizagem de práticas letradas desejadas por determinados grupos que detêm o poder disciplinar. Não é de se estranhar que a colocação dessa nova ordem posta em circulação nos documentos oficiais das reformas de maneira hegemônica e prescritiva traga dificuldades para os seus interlocutores.

A principal implicação é o reconhecimento do letramento como um fenômeno neutro, natural, singular, autônomo, visivel. Neutro, no sentido de que pode ser indiferentemente aplicado a qualquer aluno: da regiáo norte / da região sul, pobre / rico, da zona urbana / da rural, criança / jovem / adulto etc. Natural, porque resulta de um consenso social que segue a ordem regular das coisas, ignorando o diferente e o inadequado. Singular, porque está equacionado a uma prática universalizante cujo interesse é homogeneizar o saber do aluno, conduzindo-o a um único lugar - o da cultura letrada, canônica, dominante, sem atender aos interesses e às necessidades comunicativas de grupos específicos. Autônomo, porque ocorre de modo descontextualizado, atribuindo à escrita características intrínsecas, responsáveis pelo desenvolvimento cognitivo. Visivel, pelo poder e legitimação que ao letramento canônico (letramento cultural) é atribuído.

No que diz respeito aos gêneros textuais, a compreensão deflagrada é a de que estes são unidades textuais dadas, estáticas, descontextualizadas, com características facilmente identificáveis, prontas para serem ensinadas. $\mathrm{O}$ gênero, porém, não se constitui num fenômeno simples e puro. Conforme atestam estudos de vários autores (JOHNS, 2006), ele é afetado por uma rede de variáveis que operam juntas, tornando-o complexo e multifacetado. 


\section{Letramento: complexidades}

Enxergar o letramento como algo 'singular' é esquecer que a vida social é permeada por linguagem de múltiplas formas e destinada a diferentes usos. Nela, são veiculados gêneros diversos que são praticados por diferentes pessoas nas mais diversas atividades sociais, orientadas a partir de propósitos, funçôes, interesses e necessidades comunicativas específicas, não obstante a compreensão de que alguns textos são considerados canônicos e, por isso, mais legitimados que outros, socialmente. E é exatamente porque se constitui como algo 'plural' que vale a pena problematizar, examinando as diversas facetas que o constituem e as razóes por que esse fenômeno tem se tornado um verdadeiro 'campo de batalha’ no domínio pedagógico.

Para entender essa 'guerra de letramentos' (SNYDER, 2008), reflitamos sobre alguns princípios que são centrais à perspectiva dos 'novos estudos de letramento', conforme referidos por pesquisadores estrangeiros. Aqui no Brasil, são denominados, simplesmente, 'estudos de letramento' (OLIVEIRA; KLEIMAN, 2008, p. 7).

Nesses estudos argumenta-se que os letramentos, vistos como práticas sociais, necessitam ser melhor entendidos nos seus contextos sociais e históricos; são fruto de relações de poder; servem a propósitos sociais na construção e troca de significados; formatam e são formatados pela cultura; sofrem interferência de posições ideológicas, podendo estas serem explícitas e implícitas; são dinâmicos à medida que são determinados por injunções de natureza econômica (globalização), tecnológica (recursos da mídia e da internet), política (políticas públicas de educação) e histórica (certas práticas valorizadas numa determinada época que perdem o seu valor noutro tempo). São, enfim, múltiplos, dêiticos, ideológicos e críticos (BAYNHAM, 1995; LEU et al., 2004). Analisemos alguns desses princípios.

\section{Os letramentos são múltiplos}

A valorização dos usos da leitura e da escrita como práticas sociais por oposição à compreensão do letramento visto como um modelo autônomo e homogeneizante, encapsulado unicamente no processo de escolarização que enfatiza o ler e o escrever como uma habilidade, deu lugar à compreensão de um novo conceito, de natureza plural - letramentos. Fruto da virada social nas pesquisas sobre linguagem (GEE, 1996), os estudos de letramento reenquadraram-se, passando a destacar a complexidade da vida social, a pluralidade dos contextos sociais e culturais, a força das mudanças sociais e a implicação dessas mudanças 
nas práticas de letramento cotidianas. Nesse novo quadro, os letramentos locais ganharam importância teórica e, em consequência, diferentes mundos de letramento (BARTON, 2000) têm sido explorados e tornados visíveis. Uma compreensão sistemática de toda a complexidade e multiplicidade a que as práticas de letramento estão vinculadas pode ser percebida em três dimensões: 1) os diferentes contextos de atividade; 2) as atividades particulares da vida cultural; e 3) os diferentes sistemas simbólicos.

Não há dúvida de que as práticas de letramento que ocorrem nos variados contextos - casa, escola, igreja, rua, lojas, empresas, órgãos oficiais, dentre outros - atendem a funções e propósitos diferentes. Um bilhete que circula no ambiente familiar não apresenta as mesmas características de outro que é produzido, por exemplo, num local de trabalho, ou mesmo na escola. 'O que' se lê e o 'como' se lê são fortemente determinados pelo 'lugar' de onde lemos. Não lemos, por exemplo, a Bíblia em família do mesmo modo que a lemos na igreja. Nesta, o caráter evangelizador supera o interesse formativo, moral, ético que, na família, é esperado e alimentado.

Sabemos que o mundo é textualizado. Leitura e escrita estão em toda parte. O que circula, portanto, na rua ou em ambientes comunitários são modos de inscrição específicos (placas, propagandas, faixas, outdoors, fachadas etc.) de grande força comunicativa e que, por isso, merecem atenção. Consumir e saber produzir os inúmeros textos que se distribuem nos mais variados contextos sociais significa não apenas ter acesso a essas práticas comunicativas mas também assumir uma forma de poder que a muitos é negada.

Entender que o letramento é mediado por textos implica naturalmente ter consciência de que o uso de determinados textos depende do sistema de atividades no qual as pessoas estão inseridas, noutros termos, depende dos papéis que as pessoas exercem e do que elas necessitam fazer por meio desses textos em determinadas situaçõos. Esse sistema, gerado nas instituições e domínios particulares da vida cultural (academia, unidades de trabalho, entidades religiosas, sindicatos, clubes etc.), determina que gêneros escolher e usar em certas situaçôes comunicativas para atingir determinados propósitos. Em razão disso, os gêneros, conforme afirma Bazerman (2005, p. 31), "são parte do modo como os seres humanos dão forma às atividades sociais". Nessas atividades, os papéis que as pessoas exercem determinam que competência leitora e escritora elas devem ter.

Se, no exercício do seu trabalho, cabe a um médico preencher prontuários com informações de seus pacientes, prescrever receitas com indicação de medicamentos, ler bulas de remédios, ler literatura especializada a respeito de 
casos clínicos que lhe interessem, registrar ordens e ocorrências hospitalares, escrever artigos científicos etc., cabe a um professor, no ensino de uma disciplina, assumir a tarefa de elaborar programas, exercícios, fichamentos de textos para apresentação didática, planos de aula, testes de avaliação, comentários e notas sobre a produção dos alunos, boletins de notas e registros de conteúdo, avisos, textos para apresentação em aula (no recurso de Power Point), e-mails etc., ler material impresso (livros, revistas, jornais), pesquisar na internet textos informativos relativos ao conteúdo da aula etc. Os exemplos aqui focalizados salientam a natureza relacional existente entre situação, atividade e participantes em eventos de letramento.

Nos dias atuais, o que as pessoas fazem com o letramento e o modo como este é formatado tem sido largamente afetado pelo processo de globalização, pelas exigências de uma economia altamente competitiva, pelos meios de comunicação de massa e, naturalmente, pelo aparecimento da internet, vista como elemento central no fluxo e no acesso da informação. $\mathrm{Na}$ chamada 'era da informação', a disponibilidade cada vez maior de recursos de comunicação e a rápida expansão das tecnologias a serviço da informação e da ação social colocam o indivíduo frente à necessidade de buscar, localizar, sintetizar e avaliar informações úteis à resolução de problemas do cotidiano (sacar dinheiro, pagar contas, comprar via internet, solicitar informaçôes e serviços via celular e / ou computador etc.).

Especificamente no domínio do trabalho, ambiente altamente competitivo, a busca de estratégias efetivas para interagir, ganhar acesso à informação e dela fazer uso para solucionar problemas ligados ao funcionamento e produtividade da organização aponta para a necessidade de 'novos letramentos' que permitam aos jovens em geral agir e interagir na 'era do conhecimento' cujo tom recai nas ideias dos indivíduos ou na sua capacidade para pensar e criar, o que exige o desenvolvimento de várias competências do ponto de vista profissional. Em função disso, países desenvolvidos têm dado prioridade a padrões de excelência na escola, investindo em políticas públicas que valorizam o 'capital humano', o que indica a necessidade de reinventar o currículo escolar no que diz respeito às competências de linguagem para as demandas de um letramento diferente. Afinal, conforme Leu et al. (2004), ensinar alguém a ler e a escrever para os 'letramentos do futuro' é uma experiência de transformação.

Nesse quadro caracterizador de uma sociedade do futuro, que tem como base os meios de comunicação de massa e o desafio de ser criativo, o letramento gráfico une-se ao letramento visual. Nessa combinação de múltiplas 
formas semióticas, a imagem deixa de atuar como um elemento que complementa ou ilustra a palavra para ser um modo estruturante do texto. Dessa forma, ela integra a mensagem, carregando em si mesma um valor semântico. Nesse tipo de gramática textual, o sentido que se atribui ao texto resulta de um 'design' mais amplo no qual se incluem caracteres alfabéticos, imagens, cores, texturas, formas em movimento, apresentados todos de modo linear, ou seja, alocados no mesmo espaço textual.

Se essa configuração textual e / ou modo de significar no texto traz um grau de complexidade maior para a formação de leitores e escritores na contemporaneidade (p. ex., leitura de gráficos, mapas, textos midiáticos), a dificuldade é crescente no chamado letramento eletrônico em que, diferentemente do letramento impresso, informaçōes em rede são interconectadas (linked) de forma não linear - hipertexto -, o que aponta para a construção de novos cenários de letramento e novos perfis de profissionais na educação.

Ainda que se reconheça no contexto escolar o desejo de explorar o mundo virtual em sala de aula, motivado por políticas de inclusão digital, o que nele se observa, entretanto, é uma espécie de 'bricolagem'. No dizer de Lankshear e Knobel (2000), a escolarização dos letramentos pós-modernos dá-se como "velhos vinhos em novas garrafas". É o caso de recontar velhas estórias por meio de uma nova tecnologia, por exemplo, utilizando-se o Power Point. Consideremos que apenas fazer uso desse recurso, ainda que interessante, não possibilita entender a funcionalidade e o valor das novas tecnologias digitais.

\section{Os letramentos são dêiticos}

Amplamente discutidos nos estudos da linguagem, palavras como agora, hoje, aqui, lá, ir, vir assumem diferentes significados dependendo do lugar e tempo em que são enunciados. Também segundo as abordagens etnográficas de letramento, a consideração desses aspectos enunciativos indica a natureza dêitica das práticas de letramento ou o seu caráter situacional, sua dimensão histórica e topográfica. Essa natureza explica por que as práticas de leitura e escrita são dinâmicas: mudam em termos de forma e função; evoluem e se transformam segundo condições sócio-históricas. Reflexão interessante a esse respeito elabora Orlandi (1988), ao defender a 'imprevisibilidade' e 'pluralidade possível' da leitura. A variação de leitura a que ela se refere contempla, por exemplo, a questão de como um único texto permite possíveis leituras em certas épocas e não em outras; textos sagrados (em sânscrito) são lidos hoje 
como pertencentes ao domínio da literatura; classes sociais e instituições selecionam, apreciam e legitimam certos textos diferentemente de outras (textos canônicos ou não); certos modos de ler circulam em determinados domínios, e não em outros (ler em voz alta ou em voz baixa, para estudo, para ocupar o tempo, para se divertir etc.); determinadas leituras e textos sofrem restrição por parte de quem lê (jovem, criança, tipo de profissional etc.).

As rápidas transformações tecnológicas que hoje se dão afetam profundamente o letramento, à medida que requerem do indivíduo novas habilidades e estratégias para se adaptar e adquirir os letramentos que emergem, além de abrir possibilidades para o uso criativo da tecnologia como uma ferramenta útil para exercer novas funções e propósitos na formatação e composição de mensagens. A natureza dêitica do letramento suscita, assim, uma nova concepção ou (re)definição do que significa tornar-se letrado.

\section{Os letramentos são ideológicos}

A postulação das noções de 'letramento autônomo' em oposição a 'letramento ideológico', sendo entendida a primeira como uma tecnologia neutra e universal, cuja aquisição, por si mesma, produz efeitos sobre o desenvolvimento cognitivo e social, e a segunda como um posicionamento sensível ao caráter sociocultural das práticas de letramento e às estruturas de poder na sociedade (STREET, 1993), suscita uma rica discussão sobre a natureza ideológica dos letramentos.

Embora se possa entender, a partir desse contraponto, que apenas esse modelo alternativo está atravessado de ideologias, como a própria adjetivação indica, apresentando-se o modelo autônomo como neutro, no sentido de que busca a universalização das práticas de letramento, e como hegemônico, por estar a serviço do poder de um grupo particular, não se trata de uma relação tão simples. Com vistas a essa relação, é importante entender que, mesmo as concepções que se apresentam como neutras (letramento autônomo), camuflam pressuposições culturais e visões particulares do mundo social, interessadas em sustentar determinadas relações de poder, sendo, por isso, ideológicas.

Há distintas formas de entender a ideologia. Conforme a teoria social crítica (THOMPSON, 1995 apud RESENDE; RAMALHO, 2006), a ideologia é, por natureza, hegemônica no sentido de que serve para produzir, reproduzir e transformar a ordem social que favorece certos indivíduos, ou mesmo, grupos dominantes. Como as ideologias se materializam nas práticas discursivas, a investigação destas incluirá sempre um componente ideológico. 
No que diz respeito às práticas de letramento, os diferentes grupos sociais buscam continuamente assegurar, por meio da agência humana, seus interesses ou valorizar as formas de ler e escrever que lhes trazem benefícios ou se constituem como um 'bem social' compartilhado entre eles. As crenças a respeito do modo como as comunidades elegem seus 'bens sociais' apontam necessariamente para um tipo de ideologia (GEE, 1994). Não há, nesse sentido, nenhuma orientação de letramento que não seja ideológica.

\section{Os letramentos são culturais}

O entendimento de que as práticas de letramento estão sempre encaixadas em específicos contextos culturais tem sido um recorrente tema de estudo particularmente no campo da pesquisa etnográfica. Essas pesquisas salientam a natureza situada dos letramentos e discutem o fato de alguns serem 'invisíveis' em relação a outros considerados 'visíveis / dominantes' (BAYNHAM, 1995, p. 246). É evidente que o letramento escolar goza de legitimação e, em razão disso, é visto como um parâmetro para avaliação dos letramentos locais. Assim sendo, as grandes críticas dirigidas aos letramentos locais referem-se às 'limitaçôes' desses letramentos, à forma 'romântica' como estes são olhados e às relaçôes que são estabelecidas entre eles e os letramentos distantes, noutros termos, entre o 'local' e o 'global'.

Em resposta à 'aparente pobreza' dos letramentos locais, inúmeros pesquisadores (STREET, 2001; 2003; BAYNHAM, 2004) observam que, embora vozes dominantes caracterizem as populações locais como 'iletradas', uma rica variedade de práticas de letramento pode ser deflagrada em comunidades marginalizadas, sejam elas situadas em ambientes rurais ou urbanos. Defendem, por isso, a necessidade de tornar visíveis as práticas de letramento cotidianas em toda a sua complexidade. Eles argumentam que o respeito que se deve ter por esses letramentos não deve ser confundido com 'uma abordagem romântica'. A verdadeira intenção não é isolar essas práticas de outras que estão 'fora', mantendo-as 'puras', mas tê-las como ponto de partida para introduzir letramentos hegemônicos, comprometidos com o progresso e a modernização. Nesse sentido, a relação local / global não é excludente. $\mathrm{O}$ global se imbrica ao local à medida que essas comunidades tencionam garantir os seus direitos e necessidades locais. Assim (re)inventada, a questão da 'instrução' passa a ser entendida como uma prática de ensinoaprendizagem situada (BAYNHAM, 2004; BARTON, HAMILTON; IVANI ̌, 2000; SZWED, 2001), em que a escrita (e, naturalmente, a leitura), por si mesma, é incapaz de resolver problemas que são inerentes à prática social. 
Ainda a respeito dessa articulação - práticas de letramento locais / práticas de letramento dominantes -, há quem discuta que os letramentos 'universalizantes' e os modos de produzir conhecimento na academia (letramento acadêmico) são, em sentido restrito, profundamente locais (BAYNHAM, 2004; LATOUR, 2000).

Trabalhar nessa (re)invenção requer a implementação de programas de letramento que respondam às aspiraçôes do grupo a que se destina, oferecendo a ele a possibilidade de usar a leitura e a escrita de forma funcional, ou seja, como um instrumento que possibilite alternativas para resolver problemas de âmbito local ou que esteja sintonizado com os desejos e sentimentos daqueles a quem está endereçado. Escutar esse 'outro' exige do professor e / ou do pesquisador na área atitudes de engajamento e de responsabilidade social, além da habilidade para se colocar como 'insider' nesses contextos.

Na prática, sabemos que articular o local ao global não é tarefa fácil. Se, por um lado, o professor enfrenta hoje o desafio de promover o conhecimento com grupos específicos que cultivam práticas e visôes do mundo muito particulares (jovens de periferia, crianças e jovens de zona rural, adultos com interesses próprios em determinadas práticas de letramento), por outro lado, há de se considerar que, com a democratização e a globalização, chegam à escola indivíduos completamente clivados pelo processo de modernização. Fazem parte de grupos cujos valores, crenças e práticas são bem específicas, mas, ao mesmo tempo, se inserem em uma 'comunidade global' cuja demanda de informação e trabalho exige deles novas competências, favorecendo ou não possibilidades de inclusão. A esses aspectos acrescenta-se a dificuldade, a que estão submetidos os professores, relativa à imposição de uma grade de conteúdos a ser ministrada no decorrer do ano letivo.

O multiculturalismo impõe ao professor uma agenda desafiadora - a de incluir numa sociedade grafocêntrica educandos pertencentes a uma tradição oral. Nesses contextos, a imposição de letramentos exógenos acaba, muitas vezes, por expulsá-los da escola ou desinteressá-los pelas práticas escolares, uma vez que fazer parte dessa cultura letrada é 'oferecer um fardo muito pesado para quem se sente incapaz' ou é almejar um futuro para quem não tem futuro'. A compreensão desse quadro exige do professor e do pesquisador outro 'enquadre' - não há possibilidade de agir sobre esse mundo se não somos capazes de 'dialogar' com ele. As pesquisas críticas e as pedagogias culturalmente sensíveis podem oferecer respostas mais efetivas para uma 'pedagogia do letramento', julgamos. 


\section{Os letramentos são críticos}

$\mathrm{Na}$ atualidade, o que se tem considerado como 'crítico' diz respeito ao modo "como as pessoas usam textos e discursos para construir e negociar identidade, poder e capital" (LUKE, 2004, p. 21). A teoria crítica está preocupada em entender as relaçôes entre poder e conhecimento e em teorizar o papel da linguagem na produção e reprodução do poder na vida cotidiana, na comunidade e nas instituições.

Assim pensando, a linguagem não é simplesmente um meio de expressão ou comunicação; é, antes, uma prática a partir da qual os aprendizes conhecem-se a si mesmos, o seu contexto sociocultural e as suas possibilidades para o futuro. Trabalhar a linguagem nessa direção envolve decodificar a dimensão ideológica dos textos, das instituiçôes, das práticas sociais e das formas culturais (por exemplo, a televisão, o cinema), para revelar seus interesses seletivos. Para isso, faz-se necessário destacar a importância das pedagogias multimodais - variedade de modos, formas locais de comunicação - e dos letramentos multivocais que capacitam aprendizes a cruzar fronteiras discursivas, sem ser penalizado pelo dominante.

Tratando do letramento crítico, estudiosos afirmam que o propósito maior dessa orientação é formar o cidadão crítico capaz de analisar e desafiar as forças opressoras da sociedade, de forma a torná-la mais justa, igualitária e democrática; capaz de lutar contra a 'cultura do silêncio' e defender a produção de um conhecimento cultural como um elemento de força no jogo de discursos conflitantes (FREIRE, 1973; McLAREN, 1988; GIROUX, 1997).

Essa concepção de letramento exerce grande poder e influência nas políticas educacionais voltadas para a formação do cidadão crítico, tanto no âmbito nacional quanto internacional. Entretanto, a sua aplicação em sala de aula impóe grandes dificuldades, principalmente no que se refere à conciliação do 'local' com o 'global'. Essa parece ser uma tarefa desafiadora para o professor e para as escolas interessadas em buscar alternativas de transformação.

O grande entrave tem sido romper com um currículo prescrito, próprio da orientação do letramento cultural (McLAREN, 1988). Neste, as unidades de estudo são selecionadas a priori, sendo o desempenho de leitura, de escrita e de outras habilidades submetido a avaliações quantitativas por programas que tencionam produzir indicadores sobre a efetividade dos sistemas educacionais (testes do ENEM, do PISA, do vestibular, entre outros). Já no letramento crítico, o currículo se define no processo de produção do conhecimento, ou seja, ele se (re)desenha a partir de questôes que emergem das práticas de letramento escolar organizadas em eventos que objetivam atender a necessidades 
de linguagem específicas de uma comunidade de aprendizes envolta em propósitos também particulares. Por exemplo: alguém que está interessado em desenvolver sua competência leitora e escritora para práticas do cotidiano - ler a Bíblia, escrever para parentes distantes, compreender instruções em situaçôes de trabalho, ou ainda exercitar seus direitos como cidadão etc. - certamente se sentirá excluído em programas de letramento cuja atenção esteja voltada para o domínio dos discursos de poder ou de assimilação das práticas canônicas. $\mathrm{O}$ atendimento a esse aprendiz pressupõe trabalhar com específicos gêneros, focalizando determinadas habilidades e mecanismos textuais.

\section{Gênero textual: teorizações}

Aberto a variados campos disciplinares, os estudos sobre gênero textual têm-se ampliado, favorecendo reflexões variadas, provenientes de epistemologias diversas, das quais floresceram estudos cognitivistas, enunciativos, interacionista sócio-discursivos, pragmático-textuais, semióticos, sócio-retóricos etc., ocasionando o crescimento de um corpo de estudos empíricos situados em domínios diversos: escolar, profissional, acadêmico, público, privado, digital, entre outros.

Colidem, nesses estudos, dois espaços: um unificador, revelado pelo entendimento compartilhado entre pesquisadores de que o gênero é uma entidade complexa e multidimensional, e outro dispersor, observado pela utilização de terminologias flutuantes e pelos cruzamentos de construtos teóricos diferentes. Em razão disso, esse construto se mostra bastante controverso e de difícil abordagem tanto para aqueles que o analisam no nível teórico quanto para os que estão interessados na sua aplicabilidade.

Em face da sua complexidade, prevê-se que o gênero textual nem "é um tipo de texto nem um tipo de situação. Antes, constitui-se numa relação funcional entre texto e contexto, ou seja, entre um tipo de texto e uma situação retórica" (COE, 2002, p. 197). Por ser multidimensional, o gênero inclui o textual, o social e o político, devendo ser analisado a partir de diferentes aspectos: formal, retórico, processual e temático. Essas dimensóes interagem e se sobrepõem fornecendo ao usuário da língua experiente um conhecimento sofisticado que lhe permite manipulá-los conforme propósitos variados. Numa análise multidimensional de um gênero, cumpre destacar vários elementos: conteúdo (tema), linguagem, estilo, formato, organização retórica (esquemática ou cognitiva), tom, aspectos visuais (cores, imagens) etc.

Um gênero é, em suma, um modo próprio de dizer que revela quem fala e de que lugar fala. Conforme observa Hyland (2005 apud JOHNS, 
2006, p. 245), "falar de um gênero significa adaptar-se a uma 'instância' de produção discursiva apropriada, manifestando uma 'voz' que leitores experientes consideram apropriada”. Como fenômenos históricos, vinculados à vida cultural e social, os gêneros textuais são profundamente dinâmicos, plásticos e imprevisíveis. Eles se transformam, se entrecruzam, surgem e desaparecem conforme determinações sociocomunicativas.

\section{Gênero textual: implicações para o ensino}

No domínio pedagógico, os professores têm-se colocado num 'mar de incertezas' frente à adoção de um conceito em relação ao qual possuem pouco esclarecimento e respaldo teórico, apesar das orientações dos PCN, e frente à necessidade de sustentação do seu trabalho com essa categoria na sala de aula. Nessa atividade, os professores continuam estabelecendo a indevida correspondência entre gênero e tipo textual, apesar de se ampararem no discurso de que estão ensinando gêneros.

No que diz respeito à didatização desse conceito, também não há, por parte das diferentes abordagens de gênero, um consenso. Os diferentes posicionamentos registrados pouco esclarecem o professor ou o ajudam na tarefa didática. Há quem afirme que o objetivo não é tornar os gêneros objetos reais de ensino, mas utilizá-los como "quadros de atividade social em que as ações de linguagem se realizam" (BRONCKART, 1999). Alguns defendem o ensino explícito dos gêneros, argumentando que estes se constituiriam em instrumentos de mudança social e empoderamento (CHRISTIE, 1999; ROTHERY, 1996). Outros problematizam o ensino prescritivo e formalístico (pedagogia explícita) dos gêneros, ao entendê-los como dinâmicos, plásticos, sujeitos a mudanças, transformações ou até ao desaparecimento. Por respeitarem o conhecimento situado e o papel do contexto na linguagem, julgam que é difícil (ou impossível) montar um modelo ou currículo com base em gêneros. Defendem, desse modo, uma "pedagogia da imersão" (JOHNS et al. 2006; KERN, 2000), argumentando que o estudo de gêneros ajuda os escreventes a descobrirem o que pode ou não ser dito ou feito por meio deles.

Estudos voltados para a instrução de escrita relacionam diversas abordagens de ensino orientadas para diferentes funçôes: abordagem funcional e comportamental - escrita para assimilação; abordagem cognitiva - escrita para autoexpressão e construção de significado; abordagem de práticas socioculturais - escrita para afirmação; abordagem de gêneros - escrita para acesso aos discursos de poder; abordagem crítica - escrita para mudança social 
(AUERBACH, 1999). Essa dispersão teórica, resultante de escolhas funcionais, indica a necessidade de novos questionamentos e posicionamentos a respeito da relação gênero e ensino.

\section{Voltando às questões iniciais (novos questionamentos)}

Parece-nos, desse modo, que pensar sobre a questão dos gêneros textuais no contexto escolar requer, antes de mais nada, compreender o que seja 'gênero' e os fenômenos que a esse construto estão vinculados, por exemplo, o do letramento, entendido como uma prática social plural e motivada por princípios de natureza ideológica. Estabelecer essa relação implica, necessariamente, perguntar: gênero, segundo que tipo de abordagem teórica? gênero para quem (no caso, que aluno)? gênero, com vistas a que concepção de letramento e, consequentemente, a que projeto político-pedagógico?

Afinal, o que o professor ensina e como ele ensina são consequência da compreensão que ele tem dos fenômenos linguísticos e do entorno que o envolve no qual se incluem os alunos com suas especificidades. Diferentes concepções de gênero e de letramento resultam em diferentes práticas. Se no letramento cultural há um acordo no sentido de que o aluno domine o maior número de gêneros, a fim de que circule, de modo legítimo, em variadas esferas discursivas, no letramento crítico, a intenção é que o aluno se aproprie daqueles gêneros (e não de muitos) que lhes sejam úteis para agir no mundo ou para fazer uso de determinadas práticas que lhes convêm em termos de necessidade comunicativa.

É importante salientar que a efetivação dessas práticas no contexto escolar vai depender das possibilidades e dos interesses de cada educando. Numa turma, por exemplo, de alunos com avançada idade, o interesse pela leitura e escrita está orientado por propósitos bem específicos: escrever para um filho, solicitar um serviço, reivindicar um direito, fazer uma reclamação, ler uma conta a pagar, ler a Bíblia etc. Já numa turma de jovens, o grande interesse é pelas práticas que abrem portas para o trabalho ou para capacitação profissional, incluindo-se também o desejo de um dia participar de cursos universitários. Nesse grupo, as práticas de letramento que favorecem a consciência política mostram-se muito significativas, à medida que desenvolvem o senso crítico e a vontade de participar e se engajar em causas sociais, funcionando também como um recurso que eleva a autoestima de alunos que, dada a extrema pobreza em que vivem, não acreditam na vida ou na possibilidade de participar dos bens sociais materiais e intelectuais. Programas de letramento, nesse sentido, assumem um caráter transformador. 
Entendendo-se que os gêneros são os elementos estruturadores da vida social, no letramento crítico, é a prática social o componente orientador para o trabalho didático. A natureza performativa dos gêneros coloca em questão: os gêneros podem ser ensinados? Se podem, que sentido devemos atribuir à palavra 'ensino'? Se entendemos 'ensino' como 'instrução', é evidente que não poderemos ensinar os gêneros. O que nesse sentido se ensina é a sua dimensão textual - os textos -, e fazer isso é ter uma visão parcial dos gêneros. Se o entendemos como 'imersão', assumimos que os gêneros podem ser objetos de ensino, uma vez que a sua apropriação ocorre de modo situado, orientado por propósitos reais. Esse modo de 'ensinar' com os gêneros e não sobre os gêneros requer inserir os alunos numa verdadeira 'etnografia' das práticas de linguagem (DEVITT, A; REIFF, M. J.; BAWARSHI, A., 2004) ou, conforme a proposta de Swales (1998), num trabalho 'textográfico'.

Revelam-se como uma alternativa produtiva para o trabalho com os gêneros, na direção descrita, os 'projetos de letramento', nos quais “as práticas de letramento decorrem de um interesse real na vida dos alunos, servindo para atingir algum outro fim que vai além da mera aprendizagem da língua, no seu aspecto formal" (KLEIMAN, 2000, p. 238).

Considerados como uma 'prática de letramento', os projetos se inserem num tipo de cultura escolar alternativa em que a produção do conhecimento está orientada pela abordagem de 'resolução de problemas', comumente adotada em outras áreas disciplinares. Tendo como ponto de partida a prática social, esses projetos visam atender a necessidades sociais e demandas comunicativas específicas de um determinado grupo, a partir de açôes coletivas. Para tanto, professores, alunos e outros 'agentes de letramento' (KLEIMAN, 2006) engajam-se em eventos de letramento, mobilizando recursos, conhecimentos e habilidades necessárias ao que se busca resolver. Nessa situação de ensino-aprendizagem, a sala de aula funciona como uma 'comunidade de aprendizagem' em que todos ensinam e todos aprendem, conciliando interesses, conhecimentos e sentimentos. O ensinar e o aprender nos projetos de letramento se efetivam por meio do trabalho com os gêneros, entendidos como instrumentos mediadores da ação humana no mundo - em termos didáticos, o eixo organizador das atividades com a linguagem. Nessa perspectiva, os projetos "prevêem uma concepção transdisciplinar de conhecimento, uma visão aberta ou integrada de currículo, uma ruptura em relação ao tempo e espaço lineares e a processos hierárquicos, uma concepção de aprender diferenciada que leva em conta 'formas de aprendizagem situadas', 
mobilização social, intersubjetividade, dialogismo e reflexividade" (OLIVEIRA, 2008, p. 115). A FIG. que segue destaca a rede de componentes que integram os projetos de letramento.

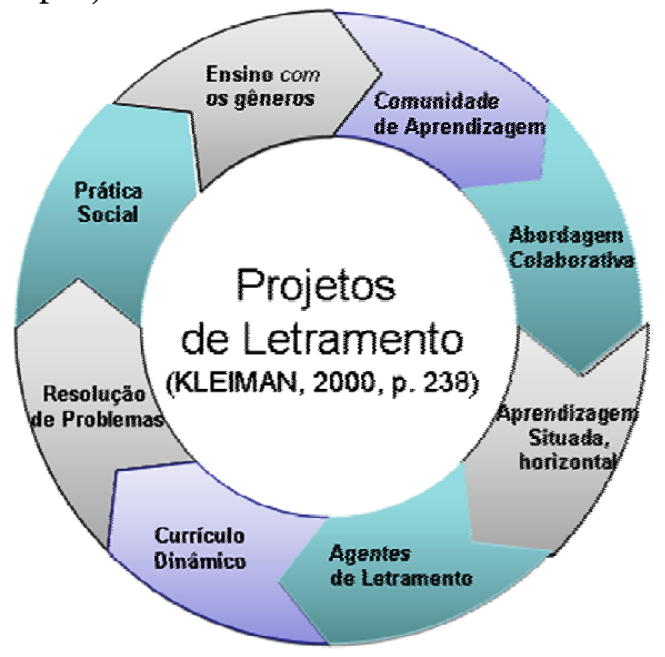

FIGURA 1 - Projetos de letramento (KLEIMAN, 2000, p. 238)

\section{Considerações finais}

A reflexão que evidenciamos neste trabalho se inicia pelo impacto que os PCN têm provocado nos professores de língua materna. A nossa experiência em programas de formação de professores indica-nos que, apesar de os professores ecoarem o discurso desse documento oficial, aludindo a várias noções nele contempladas, por exemplo, letramento e gênero, a apropriação (se assim podemos chamar) desses conceitos e a sua aplicação na sala de aula apresentam-se de forma bastante problemática. Com o foco nessa questão, refletimos sobre a complexidade teórica que é inerente a esses conceitos, relacionando-a sempre com a atividade de ensino-aprendizagem.

Inicialmente, discutimos a natureza plural do letramento, sistematizando as características que o integram e os aspectos que a ele estão relacionados: cultura, ideologia, poder, política, globalização, tecnologia. Nessa sistematização, argumentamos que os letramentos são múltiplos, dêiticos, ideológicos e críticos. A análise desses quatro princípios é feita a partir de múltiplos olhares que contribuem para a compreensão de questôes de natureza teórica, formativa e didática vinculadas às práticas de letramento no contexto escolar e de formação. 
Com vistas aos gêneros textuais, centramos nossa reflexão na dispersão que se observa relativamente a esse construto, tanto no nível teórico quanto prático. Embora haja um consenso de que o gênero é uma entidade complexa, é exatamente essa complexidade que dificulta uma tomada de posição quanto a abordá-lo como um objeto de ensino no contexto escolar. Nesse sentido, defendemos que trabalhar com os gêneros no contexto escolar exige compreender esse conceito conforme as variadas tendências teóricas, sua relação com as diferentes concepções de letramento e sua articulação com a audiência a quem está destinado. Diferentes concepçóes de gênero e de letramento resultam em diferentes práticas.

$O$ fechamento da discussão é feito com a pergunta: podem os gêneros ser ensinados? A esse respeito, nossa posição é a de que tal questionamento requer antes perguntar: qual o sentido de 'ensinar'? Se entendermos ensinar como 'instrução', julgamos que não podemos ensinar os gêneros textuais. $\mathrm{O}$ objeto que permite ser ensinado é o texto ou, talvez melhor, os mecanismos constitutivos do texto. Se ensinar é visto como um processo de 'imersão' na prática social, a resposta é positiva, tarefa que exige uma abordagem contextualizada, ou mesmo, etnográfica. Nesta perspectiva, sugerimos os projetos de letramento como práticas que contextualizam a leitura e a escrita, possibilitando abordar os gêneros não como um 'fim', mas como um 'meio'. Corresponde, noutros termos, a ensinar com os gêneros e não sobre os gêneros, o que significa considerá-los como o elemento organizador da ação de ensinar. Trabalhar, nesse sentido, requer que se organize o currículo como algo flexível, dinâmico, voltado para a realidade local.

\section{Referências}

AUERBACH, Elsa. The Power of Writing, the Writing of Power: Approaches to adult ESOL writing instruction. Focus on Basics, v. 3, Issue D, 1999.

BARTON, David. Preface: literacy events and literacy practices. In: HAMILTON, Mary; BARTON, David; IVANIč, Roz (Org.). Worlds of Literacy. Clevedon: Multilingual Matters Ltd., 1993. p. vii-x.

BARTON, David; HAMILTON, Mary; IVANIč, Roz. Situated Literacies. London: Routledge, 2000.

BAZERMAN, Charles. Gêneros textuais, tipificação e interação. Organização de Angela Paiva Dionísio e Judith Chambliss Hoffnagel. São Paulo: Cortez, 2005. 
BAYNHAM, Mike. Literacy practices: investigating literacy in social contexts. London: Longman, 1995.

BAYNHAM, Mike. Ethnographies of literacies: introduction. In: LUKE, Allan; BAYNHAM, Mike. Language and Education, v. 18, n. 4, 2004. p. 286-292.

BRASIL, MEC/SEF. Parâmetros Curriculares Nacionais: primeiro e segundo ciclos do Ensino Fundamental. Língua Portuguesa. Brasília, 1997.

BRONCKART, Jean-Paul. Atividade de linguagem, textos e discursos: por um interacionismo sócio-discursivo. São Paulo: EDUC, 1999.

COE, Richard. M. The new rhetoric of genre: writing political briefs. In: JOHNS, Ann. M. (Ed.). Genre in the classroom: multiple perspectives, 2002. p. 197-210. COPE Bill; KALANTZIS, Mary. Multiliteracies: literacy Learning and the design of social futures. London: Routledge, 2005.

CHRISTIE, Frances. Genre theory and ESL teaching: a systemic functional perspective. TESOL Quartely, v. 33, n. 4, p. 759-763, 1999.

DEVITT, Amy J.; REIFF, Mary Jo; BAWARSHI, Anis. Scenes of writing: strategies for composing with genres. New York: Longman, 2004.

FREIRE, Paulo. Education for critical consciousness. New York: Seabury Press, 1973.

GIROUX, Henry. A. Os professores como intelectuais. Rumo a uma pedagogia crítica da aprendizagem. Porto Alegre: Artes Médicas, 1997.

JOHNS, Ann M. et al. Crossing the boundaries of genre studies: commentaries by experts. Journal of Second Language Writing, n. 1, p. 234-249, 2006.

KERN, Richard. Literacy and Language Teaching. Oxford: Oxford University Press, 2000.

GEE, James Paul. Social linguistics and literacies: ideology in discourses. London: The Falmer Press, 1996.

HYLAND, K. Stance and engagement: a model of interaction in academic discourse. Discourse Studies, v. 7, p. 173-192, 2005.

KLEIMAN, Angela B. Os significados do letramento: uma nova perspectiva sobre a prática social da escrita. Campinas, SP: Mercado de Letras, 1995.

KLEIMAN, Angela B. O processo de aculturação pela escrita: ensino de forma ou aprendizagem da função? In: KLEIMAN, Angela. B.; SIGNORINI, Inês (Org.). O ensino e a formação do professor: alfabetização de jovens e adultos. Porto Alegre: Artes Médicas do Sul, 2000. p. 223-243.

KLEIMAN, Angela B. Processos identitários na formação profissional - o professor como agente de letramento. In: CORREAA, Manoel L. G.; BOCH, Françoise (Org.). Ensino de língua: representação e letramento. Campinas/SP: Mercado de Letras, 2006. p. 82-83. 
LANKSHEAR Colin; KNOBEL Michele. Mapping postmodern literacies: a preliminary chart. In: YLÄ-KOTOLA, M.; SUORANTA, J.; KANGAS, M. (Ed.). The Integrated Media Machine. Hämeenlinna: Edita, v. 2, 2000. Disponível em: <http://www.literacyandtechnology.org/v1n1/lk.html>. Acesso em: 5 fev. 2007.

LATOUR, Bruno. Ciência em ação: como seguir cientistas e engenheiros sociedade afora. São Paulo: Editora Unesp, 2000.

LAZERE, Donald. Reading and Writing for Civic Literacy: the critical citizen's guide to argumentative rhetoric. U.S.A: Paradigm Publishers, 2005.

LEU, Donald. J. et al. Toward a theory of new literacies emerging from the Internet and other information and communication technologies. In: RUDDELL, Robert. B.; UNRAU, Norman (Ed.). Theoretical models and processes of reading. Newark, DE: International Reading Association, 2004. p. 1570-1613. Disponível em: <www.readingonline.org/newliteracies/leu/>. Acesso em: 20 ago. 2009.

LUKE, Allan. Media literacy and cultural studies. In: MUSPRATT, Sandy; LUKE, Allan; FREEBODY, Peter. (Ed.). Constructing critical literacies: teaching and learning textual practice. Cresskill, NJ: Hampton, 1997. p. 19-49.

LUKE, Allan. Two takes on the critical. In: NORTON, Bonny; TOOHEY, Kelleen (Ed.). Critical pedagogy and language learning. Cambridge: Cambridge University Press, 2004. p. 21-29.

McLAREN, Peter Lawrence. Culture or Canon? Critical Pedagogy and the Political of Literacy. Havard Educational Review, v. 58, n. 2, p. 213-234, 1988.

OLIVEIRA, Maria do Socorro. Projetos: uma prática de letramento no cotidiano do professor de língua materna. In: KLEIMAN, Angela B.; OLIVEIRA, Maria do Socorro (Org.). Letramento múltiplos: agentes, práticas, representaçōes. Natal/ RN: EDUFRN, 2008. p. 93-118.

OLIVEIRA, Maria do Socorro; KLEIMAN, Angela Bustos (Org.). Letramento múltiplos: agentes, práticas, representações. Natal/RN: EDUFRN, 2008.

ORLANDI, Eni Pulcinelli. Discurso e leitura. São Paulo: Cortez; Campinas, SP: Editora da UNICAMP, 1988.

RESENDE, Viviane de Melo; RAMALHO, Viviane. Análise de discurso crítica. São Paulo: Contexto, 2006.

ROTHERY, Joan. Making changes: developing an educational linguistics. In: HASAN, Ruqayia; WILLIAMS, Geoff (Ed.) Literacy in Society. London: Longman, 1996. p. 86-123. 
SNYDER, Ilana. The literacy wars: why teaching children to read and write is a battleground in Australia. Australia: Allen\&Unwin, 2008.

STREET, Brian V. Literacy in theory and practice. Cambridge: Cambridge University Press, 1984.

STREET, Brian V. Introduction: The new literacy studies. In: STREET, Brian V. (Ed.) Cross-cultural approaches to literacy. Cambridge: Cambridge University Press, 1993. p. 1-19.

STREET, Brian V. Introduction. In: STREET, Brian V. (Org.). Literacy and Development: Etnographic Perspectives. London: Routledge, 2001. p. 1-17.

STREET, Brian V. Abordagens alternativas ao letramento e desenvolvimento. Teleconferência Unesco Brasil sobre 'letramento e diversidade', outubro de 2003.

SZWED, John F. The ethnography of literacy. In: CUHMAN, Ellen; KINTGEN, Eugene R.; KROLL, Barry M.; ROSE, Mike (Ed.) Literacy: a critical sourcebook. Boston: Bedford/St. Martin's, 2001. p. 421-429.

SWALES, John. M. Other floors, other voices: a textography of small university building. Mahwah, NJ: Lawrence Erlbaum, 1998.

THOMPSON, J. B. Ideologia e cultura moderna. Petrópolis: Vozes, 1995.

Recebido em novembro de 2009. Aprovado em fevereiro de 2010. 